\title{
Dos meios às mediações: chaves epistêmicas, teóricas e metodológicas legadas à pesquisa de recepção
}

\author{
Jiani Adriana Bonin \\ Doutora; Universidade do Vale do Rio dos Sinos; São Leopoldo, RS, Brasil \\ jianiab@gmail.com
}

\begin{abstract}
Resumo
Neste texto abordamos algumas das orientações epistêmicas, teóricas e metodológicas propostas por Jesús Martín Barbero na obra Dos meios às mediações e refletimos sobre como alicerçaram nossas práticas investigativas no campo da recepção. No desenvolvimento desta proposta, recuperamos e explicitamos estas chaves para, então, refletir sobre modos como foram apropriadas, articuladas e operacionalizadas nas práxis de construção de pesquisas de recepção que desenvolvemos nos últimos anos no âmbito do grupo de Pesquisa Processocom. Por fim, refletimos sobre as possibilidades que elas oferecem para enfrentar os desafios colocados à compreensão das produções comunicativas dos sujeitos contemporâneos no contexto das inter-relações com as mídias digitais. As reflexões empreendidas destacam aspectos produtivos destas chaves para a construção de perspectivas compreensivas, de alicerces metodológicos e de práxis investigativas fecundas para investigar os processos de recepção midiática.
\end{abstract}

\section{Palavras-chave}

Martín Barbero. Recepção midiática. Mediações. Pesquisa de recepção. Metodologias em pesquisas de recepção.

\section{Introdução}

Em sua obra Dos meios às mediações, Martín-Barbero nos legou chaves relevantes e produtivas para pensar os processos comunicacionais, assim como o lócus da recepção, que nos interessa focalizar neste texto. Refletindo sobre esta obra, constatamos que ela continua 
oferecendo-nos bases instigantes e produtivas para pensar os processos comunicacionais contemporâneos de inter-relações das pessoas com as mídias, incluindo as digitais.

Este desafio, de refletir sobre o legado do autor, foi colocado a pesquisadores que vem trabalhando com suas perspectivas na América Latina e no Brasil por ocasião do evento Tributo a Jesús Martín-Barbero: 30 anos de De los medios a las mediaciones, realizado na Faculdade de Biblioteconomia e Comunicação da Universidade Federal do Rio Grande do Sul (FABICO UFRGS) em 20171. Na participação que realizei neste evento, na mesa intitulada Jesús Martín-Barbero no Brasil: trajetórias, pesquisas e pesquisadores, como investigadora formada num ambiente teve o pensamento deste autor como um referente crucial formativo e investigativo, fui demandada a refletir sobre seu legado em termos de bases e modos de inscrição concreta na trajetória de pesquisas em recepção das quais fui partícipe. Este texto sistematiza e amplia alguns aspectos da reflexão que realizei para aquela ocasião.

Começo por lembrar que é nuclear à proposta desenvolvida por Martín Barbero em Dos meios às mediações a compreensão de que a inteligibilidade dos processos comunicacionais não pode ser reduzida aos meios, como proposto em compreensões mediacentristas, instrumentais e funcionalistas, hegemônicas na América Latina à época em que o autor a escreve - situação esta que parece não sofrido mudanças substantivas desde a publicação da obra. Tampouco poderia ser reduzida aos sentidos ideológicos constituídos e ofertados nos produtos midiáticos, tendência presente em certas vertentes críticas que se voltaram para a análise dos discursos dos meios. A perspectiva das mediações buscaria, juntamente, superar reducionismos como estes e ampliar a compreensão dos processos comunicacionais, considerando suas multidimensionalidades constitutivas, suas complexidades e contradições.

Que chaves epistêmicas, teóricas e metodológicas nos legou esta perspectiva para pensar os processos de recepção midiática na América Latina? Este questionamento foi provocador das reflexões que sistematizo neste texto - e que certamente não esgota as possibilidades de resolvê-lo. Aqui, meu propósito se circunscreve a recuperar algumas destas chaves que considero terem sido, e ainda serem, fecundas para alicerçar compreensões aprofundadas e produtivas sobre os processos de recepção. Ao mesmo tempo, procuro apontar e refletir sobre os modos como foram sendo incorporadas em

\footnotetext{
${ }^{1} 0$ evento, ocorrido nos dias 30 de novembro e 1 de dezembro de 2017 na FABICO UFRGS, foi promovido pela Cátedra Jesús Martín-Barbero do Centro Internacional de Estudios Superiores de Comunicación para América Latina (CIESPAL de Quito), com apoio do Programa de Pós-Graduação em Comunicação e Informação (PPGCOM) da UFRGS. Reuniu pesquisadores internacionais e nacionais para um debate sobre a importância, a influência e os desdobramentos da obra no contexto latinoamericano.
} 
nossas experiências investigativas com foco na recepção, em particular naquelas que trabalhamos no grupo de pesquisa Processocom, do qual faço parte ${ }^{2}$. Por fim, procuro fazer um pequeno exercício reflexivo em termos de pensar se estas chaves podem nos ajudar a compreender, atualmente, as inter-relações dos sujeitos com as mídias digitais.

\section{Chaves do pensamento de Martín Barbero na investigação dos processos de recepção}

$\mathrm{Na}$ tentativa de contribuir para pensar o legado de Martín Barbero - aqui especificamente aquele vinculado à obra Dos meios às mediações - procuro aqui recuperar orientações que considero relevantes para investigar a comunicação e refletir sobre seus desdobramentos para pensar os processos de recepção. No que se segue, sistematizo cinco chaves presentes na obra examinada, considerando a transcendência que tiveram na renovação da construção epistêmica, teórica e metodológica das pesquisas em recepção e sua atualidade para pensar os processos comunicacionais contemporâneos marcados pela digitalização, como discutirei mais à frente.

(1) A comunicação é um processo complexo e multidimensional e a recepção uma das dimensões ou instâncias componentes deste processo. Pensar a comunicação, nesta perspectiva, inclui considerar que suas instâncias (produção, produto, recepção) se interrelacionam complexamente, em vínculos que se constituem - e só podem ser inteligíveis historicamente. Isso não significa dizer que estas instâncias não tenham lógicas diferenciadas, mas que seus entrecruzamentos e nexos constitutivos precisam ser levados em conta, assim como suas especificidades, contradições e relações conflitivas. Também não significa dizer que as relações entre instâncias sejam simétricas, como preconizado por vertentes funcionalistas; os conflitos e os poderes estão presentes nestes processos e precisam ser dimensionados para sua compreensão.

A recepção, nesta perspectiva, é uma destas dimensões ou instâncias dos processos comunicacionais, e sua compreensão demanda levar em conta, também, suas articulações com as demais. Por estas razões, é concebida por Martín Barbero como um lugar desde onde

\footnotetext{
20 Processocom (Processos comunicacionais: epistemologia, midiatização, mediações e recepção) é um grupo de pesquisa com trajetória iniciada em 2002 e está vinculado ao Programa de Pós-Graduação em Ciências da Comunicação da Universidade do Vale do Rio dos Sinos (Unisinos), São Leopoldo, Rio Grande do Sul. O grupo se dedica à “[...] fundamentação, construção e sistematização de investigações científicas [...] em Comunicação. Tem como linha central a formação de pesquisadores numa perspectiva transformadora e explora, em termos metodológicos, uma epistemologia crítica que busca articular sabedorias milenares com estratégias inovadoras para a resolução de problemas de relevância social histórica e política." (PROCESSOCOM, c2018). Para maiores informações, consultar o portal do grupo disponível em http://processocom.org.
} 
rever o processo inteiro da comunicação, sendo dialeticamente ponto de chegada e de partida do processo comunicacional.

No pensamento do autor estas inter-relações, como processos que são, para serem descortinadas, necessitam ser pensadas em perspectiva histórica. Como argumenta Maldonado (2004), o livro Dos meios às mediações é, em grande medida, uma pesquisa histórica sobre as matrizes culturais, formas históricas de larga permanência em nossas culturas latino-americanas. Isso lhe permite demonstrar, para dar um exemplo, como os gêneros vão se constituindo, no decurso de um processo histórico, em estratégias de comunicabilidade entre produção e recepção, pela incorporação e ressemantização de matrizes culturais de larga duração, que ainda seguem vigentes nas culturas contemporâneas e permitem compreender o reconhecimento e as cumplicidades que geram na recepção.

(2) Os processos comunicacionais se realizam em contextos históricos concretos sendo constituídos e constituintes destes contextos. Na visão do autor, os processos de comunicação, e, em específico, aqueles relativos à recepção, não se realizam fora, mas estão atravessados por dimensões socioculturais, políticas e econômicas históricas (entre outras) que marcam, configuram, matriciam - de diferentes formas, no concreto das realidades em que se inserem - estes processos, sendo parte das lógicas de sua inteligibilidade.

Martín Barbero (1997) reconhece, neste sentido, a crucialidade do campo cultural como lócus de "operação" dos meios e de luta pela hegemonia em nossas sociedades, como cenário de construção da dominação (como também de brechas, de contradições e de conflitos) nos processos históricos de nossas sociedades, atentando para a dimensão política imbricada no campo cultural.

Os processos comunicacionais e a recepção são, assim, pensados em seus vínculos com a ordem social. Mas esta dominação não se realiza de modo mecânico e vertical na concepção do pesquisador. Ele atenta para as contradições, os conflitos, as ambiguidades, as gretas, os paradoxos, as rupturas que também fazem parte destes processos. Estas concepções exprimem um esforço para sair da razão dualista presente no pensamento comunicacional latino-americano.

(3) Os sujeitos partícipes dos processos comunicacionais são multidimensional $e$ multicontextualmente constituídos - e estes múltiplos contextos e dimensões vividos por eles são configuradoras de suas culturas, de suas subjetividades e marcam seus processos de produção de significações. No campo propriamente da recepção, as perspectivas 
desenvolvidas pelo autor colocam a necessidade de reconhecer os sujeitos como partícipes dos processos comunicacionais. Eles são concebidos como sujeitos também produtores de significações, portanto de comunicação, ainda que desigual ou assimetricamente situados nos processos comunicacionais midiáticos - naquele momento, fundamentalmente analógicos. São pensados como sujeitos complexa e multidimensionalmente constituídos, a partir de sua imersão concreta - em trajetória - em contextos sociais, culturais, políticos, econômicos, historicamente configurados. Assim, o autor reconhece que a experiência social e vital das pessoas, constituída multidimensionalmente, é parte do processo de produção de produção de sentidos, deixa neste processo suas marcas.

Esta orientação permitiu ao pesquisador, como lembra Maldonado (2004), reconhecer dimensões importantes das culturas latino-americanas que participam dos processos comunicacionais e de recepção midiática, como as sociabilidades de bairro, de vizinhança e de família; as mesclas culturais diversas (culturas étnicas, regionais, de gênero, geracionais) presentes nas realidades latino-americanas e a persistência de matrizes culturais de larga duração, vigentes na experiência sociocultural das pessoas. Estas pluralidades e a persistência de matrizes culturais remetem aos processos de modernização, urbanização e globalização em suas concretizações desiguais em nossas sociedades mas, também, à força das matrizes culturais e de seu sentido para as pessoas.

(4) As produções de sentido no universo da recepção são múltiplas, complexas, podendo apresentar afinidades, cumplicidades, contradições, ambiguidades, resistências, apropriações e mesmo subversões em relação às ofertas simbólicas midiáticas. A perspectiva construída pelo autor reconhece que as significações produzidas no universo da recepção podem ser diversas e distintas daquelas ofertadas pela produção, manifestando processos de apropriação simbólica tática e subversiva. Mas estas relações não podem ser pensadas apenas como espaços de resistência, de subversão, de apropriação tática, posição que opacaria os meandros de ação dos poderes simbólicos dos meios. Vinculado a isso está o reconhecimento de que os nexos históricos das pessoas com os meios são formativos de habitus, elementos programadores de gostos e matriciadores de sentidos em afinidade com as propostas dos meios. Paralelamente, estas mesmas relações históricas com produtos e gêneros midiáticos podem proporcionar o conhecimento de suas gramáticas, códigos, convenções, linguagens, etc.

Assim, a proposta de Martín Barbero (1997) leva a reconhecer a recepção e as significações dos sujeitos em suas múltiplas possibilidades: de produção de seduções, de 
cumplicidades e da construção de nexos que colaboram para reprodução social mas, também e simultaneamente, como relações onde os sujeitos podem operar desvios de sentidos, ressignificações, apropriações e resistências, a depender do complexo de mediações constitutivas destes sujeitos e de seus referentes simbólicos, constituídos nos cenários concretos de trajetória e de vivências.

Estas proposições foram cruciais para combater a hegemonia dos paradigmas funcionalistas na América Latina e mesmo no Brasil. Lembremos como a noção de receptor, constituída pela perspectiva funcionalista, era redutora da complexidade da recepção e do lugar dos sujeitos nestes processos. Nesta perspectiva, fundamentada num esquema linear de comunicação, a ação dos sujeitos foi concebida a partir de pressupostos informados pelo behaviorismo e reduzida à reação a estímulos midiáticos influentes e, ou persuasivos. A dimensão social dos sujeitos foi problematizada a partir da noção de massa e, também, de estrutura social sistêmica funcional abstraída da história, na qual se inseriam como indivíduos assujeitados. Os processos comunicacionais foram reduzidos à transmissão de mensagens e suas dissonâncias ${ }^{3}$.

(5) A necessidade de produzir teorias e métodos para as problemáticas investigadas e em afinidade com os contextos concretos investigados. É relevante destacar que as proposições trabalhadas para pensar os processos comunicacionais demonstram que Martín Barbero (1997) não concebe as teorias como raciocínios prontos, mas como construções que devem ser problematizadas, reformuladas, alargadas em confronto com as realidades em investigação. 0 autor reconhece que a realidade comunicacional é dinâmica, cambiante, complexa, e não pode ser pensada desde formulações teóricas prontas e definitivas, mas desde compreensões provisórias a partir das quais tatear o campo, a maneira de um mapa noturno ${ }^{4}$.

Esta chave epistêmica desafia a aplicação facilista de teorias e modelos e assume a necessidade de sua construção artesanal, em vínculos profundos com os contextos e as situações concretas, em aproximação, confluência e confrontação com as realidades investigadas. Ela coloca a necessidade de que a realidade empírica seja perscrutada, explorada e levada em conta para a produção de compreensões afinadas com ela.

Outra orientação metodológica trazida pelo autor é que não existem métodos prontos para serem "aplicados". Toda problemática exige construções e combinações

\footnotetext{
${ }^{3}$ Uma problematização produtiva sobre os limites da noção de receptor é desenvolvida por Maldonado (2014).

${ }^{4}$ Além da obra Dos meios às mediações (Martín Barbero 1997), estas questões são singularmente abordadas em Ofício de cartógrafo (Martín-Barbero, 2002).
} 
metódicas que dependem da realidade do processo ou do fenômeno que vamos investigar. Os métodos devem articular-se solidariamente com a problemática da pesquisa e às suas dimensões compreensivas; precisam ingressar em nossas pesquisas enquanto teorias em ato, ou seja, serem considerados em sua dimensão teórica e em suas lógicas constitutivas; devem incluir especificidades relacionadas aos objetos empíricos sob investigação; as combinações, reformulações e arranjos devem considerar complexamente estas dimensões ${ }^{5}$.

Estas orientações epistémicas, teóricas e metodológicas têm fertilizado os processos investigativos de recepção que realizamos nos últimos anos ${ }^{6}$. Destacarei, no que se segue, certas práxis metodológicas que temos desenvolvido no trabalho realizado particularmente no âmbito do grupo de Pesquisa Processocom, do qual faço parte, que têm nelas um fundamento importante.

\section{O legado do autor na construção metodológica de pesquisas de recepção}

Retomo aqui uma das orientações de Martín Barbero que apontei anteriormente para refletir sobre seu desdobramento concreto nas práxis de construção das pesquisas de recepção que temos desenvolvido: não é possível, num contexto dinâmico, complexo e diverso, adotar acriticamente formulações para entender os processos de recepção, ou modelos prontos de mediações; é necessário construí-las em perspectivas complexas e em afinidade com as realidades investigadas.

Essa chave foi um dos fundamentos que nos levaram a investir esforços, ao longo dos anos de trabalho coletivo, no processo de construção das dimensões teóricas das pesquisas em confluência com observações exploratórias das realidades investigadas para construir conceitos vivos, nutridos por estas realidades e para visualizar, no complexo de

\footnotetext{
${ }^{5}$ Estas compreensões se alinham às de Bachelard (1977) e de Bourdieu, Chamboredon e Passeron (1999), autores com quem trabalhamos em relação à problemática dos métodos.

6 Nesta trajetória, nossa experiência de participação no projeto Recepção de Telenovela, coordenado pela profa. Maria Immacolata Vassalo Lopes na Escola de Comunicação e Artes da Universidade de São Paulo (ECA USP), foi um importante espaço para estudo, desconstrução, apropriação e trabalho com as proposições de Martín Barbero. O projeto tinha como objetivo investigar a recepção de telenovela por famílias de classe distintas, a partir das mediações gênero ficcional, cotidiano familiar e subjetividade. Também como proposta vertebral estava a experimentação de métodos e procedimentos diversos para investigar a recepção. 0 projeto representou um esforço singular no sentido de trabalhar com as mediações a partir do concreto das realidades investigadas, de teorizar as mediações de modo complexo e de produzir, experimentar e articular métodos e procedimentos apropriados para a observação das mediações estudadas.
} 
mediações presentes no mundo empírico, aquelas que ganham relevância para a compreensão dos processos concretamente estudados.

Ela também foi um pressuposto orientador de processos metodológicos voltados à exploração empírica das realidades investigadas, nos focos de interesse das pesquisas, que permitissem alimentar a construção dos desenhos investigativos. Isso para fazer com que sua construção compreensiva e sua operacionalização pudessem se realizar em vínculo confluência e confrontação - com o mundo empírico sob investigação. A práxis de pesquisa exploratória se instituiu como um processo metodológico vertebral no amadurecimento e na concretização de nossas propostas investigativas, em múltiplas dimensões, para perscrutar e pensar adequadamente as complexidades do concreto ${ }^{7}$.

A práxis de pesquisa teórica ${ }^{8}$ tornou-se um eixo central em nossos trabalhos de construção investigativa, tanto individuais como coletivos, para elaborar devidamente as perspectivas de compreensão da recepção e das mediações ${ }^{9}$. A pesquisa teórica demanda entrar com força na rede de raciocínios dos autores para entender o tecido de suas ideias; logo, desmontar, problematizar e reformular argumentos e perspectivas, ações reflexivas estas que devem ser nutridas pelas pistas e constatações empíricas que as explorações oferecem. Assim, esforçamo-nos na construção artesanal dos raciocínios teóricos em confluência e confrontação com a realidade empírica sob investigação.

0 reconhecimento profundo da necessidade de perspectiva histórica para compreender os processos comunicacionais na recepção, presente nas propostas de Martín Barbero, foi um dos fundamentos relevantes para a inclusão da práxis de contextualização como um expediente metodológico fundamental de nossas investigações ${ }^{10}$. A partir da pesquisa de contextos múltiplos, buscamos realizar uma reconstrução de aspectos comunicacionalmente relevantes para entender os processos de recepção investigados; para concretizar e perspectivar historicamente a constituição das mediações, em sua natureza

\footnotetext{
${ }^{7}$ Em Bonin (2013b) pode ser consultada uma reflexão que realizamos sobre os pressupostos, o sentido e a construção de práticas de pesquisa metodológica que desenvolvemos ao longo dos anos nas investigações realizadas no grupo de pesquisa Processocom. Outras práticas aqui tratadas foram refletidas em Bonin (2011).

${ }^{8}$ Uma reflexão sobre a pesquisa teórica realizada por Efendy Maldonado fundamenta e sistematiza perspectivas trabalhadas no grupo Processocom. Está publicada em Maldonado (2011).

9 Nesta perspectiva, na trajetória de nossas pesquisas, os processos de recepção foram pensados em articulação com mediações relativas à classe social, à cotidianidade familiar, ao cotidiano rural, a culturas étnicas, juvenis, de gênero, geracionais presentes em contextos concretos da realidade brasileira, entre outras dimensões. Mas também, na constituição de culturas midiáticas, de seus gêneros e gramáticas específicas.

10 Uma reflexão sobre a importância dos contextos e de sua recuperação como componente crucial de nossas pesquisas está sistematizada em Maldonado (2011).
} 
comunicativa, assim como dos processos de midiatização, nos seus atravessamentos históricos nas culturas, realidades e sujeitos sociais investigados.

Este reconhecimento da necessidade de incluir a perspectiva histórica em nossas pesquisas também nos levou a investir em ações de construção, fundamentação, experimentação e realização de métodos de investigação de perspectiva histórica junto aos sujeitos. Experimentações de variadas modalidades de entrevistas com perspectiva histórica foram sendo implementadas nas pesquisas para assumir esta chave epistêmica de compreensão dos processos de recepção. Entre elas estão as histórias de vida comunicacionais/midiáticas, construídas para descortinar as trajetórias de constituição comunicacional e midiática de sujeitos (em dimensões étnicas, de gênero etc.), de suas culturas e subjetividades ${ }^{11}$ e as histórias de vida midiática, centradas na recuperação das trajetórias de relações com os meios e na apreensão da constituição de suas culturas midiáticas $^{12}$.

A perspectiva de pensar a recepção como instância articulada a outras do processo comunicacional (produção, produtos, recepção) colocou um forte desafio às investigações em nosso campo e, também, às práticas de nosso grupo de investigação: como lidar com esta complexidade de instâncias articuladas e constitutivas da inteligibilidade da recepção, nas condições concretas de nossas pesquisas - marcadas por restrições em termos de temporalidades, recursos, pessoas envolvidas, entre outros fatores?

$\mathrm{Na}$ impossibilidade de operar com a complexidade das multi-dimensões constitutivas dos processos de recepção, fomos nos orientando para a construção de recortes reflexivamente construídos. Neste sentido, fomos refletindo que estes recortes precisam ser operados de maneira a não negligenciem sua condição de parcialidade e, ao mesmo tempo, de vinculação à totalidade - que permaneceria inscrita como marcas neste recorte. Também, que precisam ser operados em afinidade com as realidades pesquisadas, considerando dimensões relevantes para os processos de recepção concretamente pesquisados. Na constituição destes recortes, aspectos relevantes constitutivos das demais instâncias do processo passariam a ingressar na pesquisa como contextos - sendo reconstruídos a partir de fontes bibliográficas, documentais e de outros procedimentos metodológicos produtivos para dar conta destas contextualizações devidamente.

\footnotetext{
11 Tivemos como antecedente deste processo a história de vida cultural, procedimento criado para fazer emergir aspectos relativos às trajetórias de vida cultural dos sujeitos (cultura formativa, oral, letrada, musical, midiática) experimentado no projeto Recepção de telenovela, cujos resultados foram publicados em Lopes et al. (2002).

12 Em Bonin (2013a) sistematizamos uma reflexão metodológica sobre estes procedimentos de perspectiva histórica trabalhados em pesquisas de recepção.
} 
A complexidade dos processos de recepção, pensados em afinidade com a perspectiva de Martín Barbero, nos instigou a trabalhar, no plano metodológico, com a construção e experimentação de arranjos complexos, multifocais, multitransmetodológicos ${ }^{13}$. Na dimensão metodológica, esta perspectiva orienta a pesquisa para um investimento na confluência lógica e conceitual de vários métodos, de acordo com as necessidades estabelecidas pelas problemáticas investigadas (MALDONADO, 2013).

É importante mencionar que a trajetória de nossas pesquisas no contexto do Programa de Pós-graduação em Ciências da Comunicação (PPGCC) da Unisinos e do grupo de pesquisa Processocom se vincula à área de concentração Processos midiáticos. Este foco reconhece a intensa penetração das mídias nos diversos campos e domínios sociais e as consequentes transformações acarretadas, assumindo a necessidade de pensar os processos de midiatização social.

Pensar a midiatização como componente da problemática de recepção nos exigiu olhar com acuidade as formas como as mídias se inscrevem na experiência social, nas culturas, nas identidades, nas subjetividades das pessoas e como matriciam suas produções de sentidos. No trabalho do Processocom, o desafio de investigar a recepção considerando os processos de midiatização social não significou, para nós, que a perspectiva das mediações tivesse que ser abandonada; em nossas construções investigativas, ela foi sendo trabalhada em articulação com a problematização relativa à midiatização. Assumimos que a centralidade da mídia, sua ação configuradora de habitus, ethos e matrizes de produção de sentidos, que nos interessava reconhecer e desvendar neste foco de concentração, se realizaria em suas imbricações societais, em múltiplas dimensões, que deveriam ser consideradas e perspectivadas diacronicamente.

As próprias releituras feitas por Martín Barbero de sua obra, reconhecendo a tecnicidade como dimensão estrutural, alimentaram nossas reformulações no modo de perspectivar as mediações e assumir os processos midiáticos como foco central. No âmbito dos sujeitos, as dimensões mediadoras dos processos de recepção que investigamos foram sendo reconhecidas como simultaneamente atravessadas e matriciadas (de modos desiguais, a depender das experiências concretas) pelos processos de midiatização constituídos nas suas trajetórias de vida. No plano metodológico, os processos e

\footnotetext{
13 Na trajetória investigativa que desenvolvi, vinculada à problemática da recepção, a pesquisa de doutorado, intitulada Telenovela, identidade étnica e cotidiano familiar, representou um momento importante de experimentação de arranjo multimetodológico para investigação de problemáticas concretas em pesquisa de recepção. Uma síntese desta construção metodológica pode ser visualizada em Bonin (2004).
} 
procedimentos investigativos com os sujeitos nos exigiram dar maior acuidade ao foco midiático, sem deixar de trabalhar sua imbricação com dimensões comunicacionais constitutivas dos processos de recepção investigados.

\section{A digitalização como desafio}

Contemporaneamente, vivenciamos um contexto de mudanças profundas no campo da recepção, por força de processos como a digitalização, a convergência e a mobilidade. Frente a este cenário, é pertinente nos questionarmos se as proposições que examinamos, presentes na proposta de Martín Barbero, ainda são produtivas para pensar esta renovada realidade. Observando os processos contemporâneos de digitalização, percebemos atualmente um embaralhamento das instâncias comunicacionais (antes discernidas como produção, produtos, recepção); a emergência de novas formas dos sujeitos vincular-se aos processos comunicacionais digitais, a partir das quais podem produzir comunicação nos ambientes digitais.

Essa redefinição das instâncias não esvazia, em nossa compreensão, a necessidade de pensar a comunicação digital como processo complexo, que tem chaves de inteligibilidade não apenas nos ambientes digitais ou na produção comunicacional dos sujeitos. Para entender os usos e apropriações realizados por sujeitos, grupos, coletivos etc., é necessário tomar em conta múltiplas dimensões que configuram estes processos comunicacionais digitais. Para citar alguns temos, por exemplo, os interesses e as estratégias constituídos pelas corporações que ofertam plataformas, aplicativos e ambientes digitais; as práticas de vigilância e de controle ${ }^{14}$, os processos de cooptação do trabalho de produção comunicacional dos sujeitos; as lógicas dos ambientes digitais que se inscrevem como dimensões constituintes dos processos comunicacionais (algoritmos, lógicas de plataformas, recursos e funcionalidades). Estas novas lógicas exigem pensar como se reatualizam os processos de poder e dominação, seu sentido político, as cumplicidades estabelecidas com estes ambientes etc. Também, as potencialidades ampliadas de produção comunicativa, de manifestação de dissidência, de desvios e de resistências à ordem social constituídas nos usos comunicacionais digitais de grupos, coletivos e redes.

Os processos comunicacionais digitais também não podem ser entendidos fora dos contextos societais e históricos onde se inserem - aspecto fundamental da proposta de

${ }^{14}$ Uma problematização relevante sobre as lógicas de vigilância e controle é feita em Mattelart e Vitalis (2014). 
Martín Barbero (1997). Temos que considerar, neste eixo, que eles entrelaçam de formas inéditas múltiplos contextos, micro e macrossociais, globais e locais, que precisam ser pensados nas investigações.

No contexto da digitalização, pensar os sujeitos, grupos e coletivos que investigamos como multidimensionalmente constituídos, sendo estas múltiplas dimensões marcantes nos processos de produção comunicativa continua sendo, em nossa perspectiva, uma proposta produtiva e necessária para entender de modo denso a comunicação e seu sentido nos ambientes digitais. Ainda que a digitalização seja um processo em expansão, constitutivo e configurador das nossas sociedades (em graus diversos, a depender de distintos fatores), ela se realiza diferenciada e desigualmente em nossas realidades e em imbricação com distintas dimensões da existência dos sujeitos, grupos e coletivos, que tem configuração no tempo portanto necessitam de mirada histórica. Ainda sobre este ponto, pensamos ser relevante prestar atenção à trajetória de vínculos com as mídias em geral, e com as mídias digitais em particular, pois o processo de midiatização, incidindo na trajetória dos sujeitos, constituíram ethos, habitus, competências e gostos que também estão implicados nas produções comunicacionais digitais dos sujeitos.

Uma das alterações que as mídias digitais trouxeram em relação à comunicação massiva é relativa ao controle dos produtos simbólicos ofertados, com a abertura de possibilidades de produção comunicacional aos sujeitos. Mas isso não pode ser lido de maneira simplista como a liberação do polo da emissão. Pensamos que as possibilidades de produção comunicacional dos sujeitos nesta nova ambiência digital complexifica seu lugar e sua agência nestes processos. A releitura do pensamento de Martín Barbero nos instiga produtivamente no sentido de pensar as produções dos sujeitos nas mídias digitais em chave complexa, em seus conflitos e contradições que podem contribuir para a reprodução da ordem social, mas, também, em suas possibilidades renovadas de resistência, de desvios, de apropriações e de reinvenções da ordem social.

Finalmente, a chave epistêmica de produzir teorias em afinidade com os contextos concretos, presente na obra de Martín Barbero, é fundamental, sobretudo neste contexto de transformações. Ela demanda esforços redobrados de nós, pesquisadores da recepção, num tempo em que as reconfigurações societais produzidas pelo processo de digitalização apresentam novos dinamismos e complexidades que exigem sofisticação teóricometodológica, afinada com as realidades em transformação. Também nos convoca a trabalhar para entender estas realidades em chave complexa, densa para contrapor certas 
tendências que, no campo comunicacional, renovam-se e fazem proliferar perspectivas funcionalistas, tecnicistas e redutoras da compreensão da sua complexidade.

\section{Referências}

BACHELARD, Gaston. A epistemologia. Rio de Janeiro: Zahar, 1977.

BONIN, Jiani Adriana. A dimensão metodológica na pesquisa comunicacional e os desafios da observação em perspectiva histórica. In: MALDONADO, Alberto Efendy; BONIN, Jiani Adriana; ROSÁRIO, Nísia Martins do. Perspectivas metodológicas em comunicação: novos desafios na prática investigativa. Salamanca: Comunicación social ediciones y publicaciones 2013a. p. 58-77.

BONIN, Jiani Adriana. A pesquisa exploratória na construção de investigações comunicacionais com foco na recepção. In: BONIN, Jiani Adriana; ROSÁRIO, Nísia Martins do (Org.). Processualidades metodológicas: configurações transformadoras em comunicação. Florianópolis: Insular, 2013b. p. 23-42.

BONIN, Jiani Adriana. Revisitando os bastidores da pesquisa: práticas metodológicas na construção de um projeto de investigação. In: Maldonado, Alberto Efendy (Org.).

Metodologias de pesquisa em comunicação: olhares, trilhas e processos. 2ed. Porto Alegre: Sulina, 2011, p. 19-42.

BONIN, Jiani Adriana. Estratégia multimetodológica de captação de dados em pesquisa de recepção: a experiência da investigação Telenovela, identidade étnica e cotidiano familiar. Rastros, Joinville, v. 1, p. 6-18, 2004.

BOURDIEU, Pierre; CHAMBOREDON, Jean-Claude; PASSERON, Jean-Claude. A profissão de sociólogo: preliminares epistemológicas. 2. ed. Petrópolis: Vozes, 1999.

LOPES, Maria Immacolata Vassalo de et al. Vivendo com a telenovela. Mediações, recepção e teleficcionalidade. São Paulo: Summus, 2002.

MALDONADO, Alberto Efendy. Perspectivas transmetodológicas na pesquisa de sujeitos comunicantes em processos de receptividade comunicativa. In: MALDONADO, Alberto Efendy (Org.). Panorâmica da investigação em comunicação no Brasil: processos receptivos, cidadania e dimensão digital. Salamanca: Comunicación Social Ediciones y Publicaciones, 2014. p. 17-40.

MALDONADO, Alberto Efendy. A perspectiva transmetodológica na conjuntura de mudança civilizadora em inícios do século XXI. In: MALDONADO, Alberto Efendy; BONIN, Jiani Adriana; ROSÁRIO, Nísia Martins do (Org.) Perspectivas metodológicas em comunicação: novos desafios na prática investigativa. 2. ed. Salamanca: Editorial Comunicación Social, 2013. v. 1, p. 17-45. 
MALDONADO, Alberto Efendy. Pesquisa em comunicação: trilhas históricas, contextualização, pesquisa empírica e pesquisa teórica. In: Maldonado, Alberto Efendy (Org.). Metodologias de pesquisa em comunicação: olhares, trilhas e processos. 2. ed. Porto Alegre: Sulina, 2011. p. 277-303.

MALDONADO, Alberto Efendy. Trajetórias metodológicas suscitadoras. Ciberlegenda, Rio de Janeiro, n. 14, p. 1-18, 2004.

MALDONADO, Alberto Efendy. Produtos midiáticos, estratégias, recepção: a perspectiva transmetodológica. Ciberlegenda, Rio de Janeiro, n. 9, p. 1-23, 2002.

MARTÍN BARBERO, Jesús. Dos meios às mediações: comunicação, cultura e hegemonia. Rio de Janeiro: UFRJ, 1997.

MARTÍN BARBERO, Jesús. Ofício de cartógrafo. México: Fondo de Cultura Econômica, 2002.

MATTELART, Armand. VITALIS, André. De Orwell al cibercontrol. Barcelona: Gedisa, 2014.

PROCESSOCOM. Quem somos. São Leopoldo, c2018.

\title{
From the Media to mediations: epistemic, theoretical and methodological keys bequeathed to reception research
}

\begin{abstract}
In this text, we approach some epistemic, theoretical and methodological guidelines proposals from Jesús Martín Barbero in the book From the Media to mediations and reflect about how they found our investigative practices in the reception field. In the development of this proposal, we recover and explicit those keys to, then, reflect about the manners they were appropriated, articulated and operationalized in the praxis of the building of reception researches that we developed in the last few years at Research Group Processocom. Lastly, we reflect about possibilities that they offer to face the challenges that emerge to the comprehension of communicative products by contemporary subjects in the context of inter-relation with digital media. The reflections that are made highlight productive aspects of those keys for the development of comprehensive perspectives, of methodological foundations and fruitful investigative praxis to investigate the processes of media reception.
\end{abstract}




\section{Keywords}

Martín Barbero. Media reception. Mediations. Reception research. Reception research methodology.

Recebido em 14/03/2018

Aceito em 03/05/2018 